\title{
O CONCEITO DE MUNDANIDADE DO MUNDO EM SER E TEMPO.
}

\author{
Crislane Barreto Santana ${ }^{1}$, Tatiane Boechat A. Zunino ${ }^{2}$ \\ 1. Bolsista PROBIC/UEFS, Graduando em Filosofia, Universidade Estadual de Feira de \\ Santana, e-mail: crislanebarretto@gmail.com \\ 2. Orientadora, Departamento de Ciências Humanas e Filosofia, Universidade Estadual de \\ Feira de Santana, e-mail: tatiboechat@uefs.br
}

PALAVRAS-CHAVE: Dasein, instrumento, significância.

\section{INTRODUÇÃO:}

O trajeto traçado neste projeto de pesquisa - o conceito de "mundanidade do mundo" (die Weltlichkeit der Welt) - consiste na análise do conceito ontológico-existencial de "mundanidade" (Weltlichkeit) como caráter do próprio existente humano (Dasein). Com isto, tomamos como tema investigativo o conceito de ser-no-mundo (in der Welt sein), que é um fenômeno da cotidianidade do Dasein. Esse termo é aplicável exclusivamente ao Dasein em um determinado aspecto de mundo próprio a ele. Deste modo, devemos perceber o mundo como instância em que este ente se lança em um jogo com seu próprio ser, fazendo-nos notar os múltiplos modos de lidar com os entes no mundo ou, mais especificamente, com os entes intramundanos.

\section{MATERIAL E MÉTODOS OU METODOLOGIA (ou equivalente)}

Foram utilizados livros, artigos, resenhas, teses, dissertações, dicionários e vídeo-aulas como ferramentas complementares da pesquisa filosófica. A metodologia adotada é a da pesquisa bibliográfica aliada à análise textual, cuja finalidade se constitui numa consulta sistemática e cuidadosa de escritos correlatos ao tema e respectivo objetivo do presente resumo. O desenvolvimento da pesquisa tem como passo investigativo fundamental a leitura e análise de textos e conferências de autoria do filósofo Martin Heidegger, assim como comentários de estudiosos ligados à questão proposta. Consultamos também recursos digitais da literatura secundária, ao parecer-nos pertinente.

\section{RESULTADOS E/OU DISCUSSÃO (ou Análise e discussão dos resultados)}

Pensar a Mundanidade do Mundo é refletir sobre a própria identidade da filosofia heideggeriana. O filosofo alemão Martin Heidegger, pensou questões esquecidas e pertinentes a sua época que passava por inúmeras crises, principalmente no campo das ciências. Heidegger em 1927 publica Ser e Tempo (Sein und Zeit), obra que é considerada por muitos um marco na filosofia do autor e do século XX. Heidegger nela expõe uma questão que se arrastará por toda sua trajetória filosófica, a saber, o pensamento do sentido do ser.

Para tratar adequadamente a questão, o autor propõe uma analítica existencial do existente humano que co-pertence à questão fundamental levantada por ele. A analítica existencial se justifica na medida em que o existente humano é o único ente que carrega em si a possibilidade de questionar e compreender o ser dos outros entes ao mesmo tempo em que está em jogo o seu próprio ser. Desse modo, Heidegger traz a Ontologia Fundamental como base a esta investigação aliado ao método fenomenológico e a uma hermenêutica filosófica; tais conceitos (Fenomenologia e Hermenêutica) foram resgatados e propostos para assim integrar o plano investigativo da filosofia heideggeriana.

Nota-se que nos parágrafos introdutórios de Ser e Tempo, Heidegger nos fala da "necessidade de uma retomada explícita da questão do ser" onde o mesmo aponta que a tradição filosófica (a tradição metafísica) erroneamente a interpretou. Sein und Zeit nos 
oferece a perspectiva de perguntarmos novamente pelo sentido do ser, ao passo que, reaviva a ontologia como caminho de investigação sobre o ser e o seu sentido, assim se constitui a peculiaridade do questionar ontológico heideggeriano.

A partir do desenvolvimento de uma Ontologia Fundamental, Heidegger traz para o centro da investigação o existente humano, que agora, não mais será referido como homem e, sim, como Dasein, único ente capaz de perguntar e questionar sobre o sentido do ser, e que possui em sua constituição a abertura ao sentido. Após apresentarmos em notas introdutórias o projeto ontológico de Ser e Tempo e suas implicações, a saber, a questão fundamental sobre o sentido do ser, nos ateremos a uma das características fundamentais do Dasein, o ser-no-mundo. Iniciaremos esta exposição dizendo que o ser-no-mundo é estrutura fundamental para o existir do Dasein, na medida em que este ente desde sempre já se encontra lançado no mundo e guarda uma relação recíproca para com seu próprio existir. É preciso salientar que não há rupturas nesta relação, não estamos lidando, com duas "coisas" distintas, Dasein e mundo, estamos sempre nos referindo a uma unidade. Por isto o conceito de ser-no-mundo, simboliza uma união que desde sempre já está implícita.

Próximos à questão central deste relatório, exporemos agora, como Heidegger introduz a ideia de mundanidade do mundo aliado ao modo do Dasein como ser no mundo. Para tanto, nos propusemos entender como se dá esse encontro e como adentraríamos ao conceito existencial mundo. Desta maneira, lançaremos mão do método fenomenológico exposto no $§ 7$ de Ser e Tempo para explicarmos como apreender o fenômeno do mundo: a mundanidade do mundo.

Deste modo, para compreendermos a imersão do método fenomenológico dentro da ontologia heideggeriana, trataremos da compreensão como um dos existenciais fundamentais do Dasein, pois é no compreender que ele projeta seu ser para as possibilidades significativas de mundo. Nas análises textuais de Ser e Tempo, nota-se especialmente no $\$ 31$ que a compreensão do Dasein é um poder-ser que se caracteriza como "possibilidade". Ou seja, a descrição do poder-ser está vinculada à noção de possibilidade do modo de ser do existente humano, que reside na ocupação com os entes e com os outros Dasein. De tal modo, podemos dizer que essa ocupação é a via de acesso à abertura, ao campo das significações. Notamos nesse contexto que a compreensão do ser está associada ao comportamento para com os entes, comportar-se é relacionar-se com sentido, assim este fenômeno é concebido pelo Dasein que compreende e interpreta mundo. Heidegger dirá que as possibilidades aparecem como determinação ontológica mais originária, pois é aliado ao método fenomenológico que permite-lhe a visão capaz de compreender o poder-ser e propiciar pensar esta abertura ao mundo. Portanto, o aparecer do fenômeno está diretamente ligado ao caráter constitutivo da abertura do Dasein, que lançado ao mundo mantém-se em relação intrínseca às projeções nos cenários interpretativos do seu modo fático. A vida fática do Dasein é uma das estruturas fundamentais da sua existência, pois em si articulam-se as experiências do mundo circundante que, de um modo próprio, efetivam-se na dimensão das aparições dos fenômenos, ou seja, daquilo que lhe vem ao encontro, aparecendo-lhe em significações, "exigindo" do Dasein modos de interpretação dentro das circunstâncias na qual se encontra inserido. Assim o fenômeno pode ser percebido como a descrição do movimento do mostrar-se: trata-se do modo como às coisas se manifestam, a saber, o caráter de ser das "coisas" que aparecem ao Dasein e se dão dentro do mundo; na vida fática e neste âmbito acontecem o mostrar-se do fenômeno como compreensão que possibilita os modos relacionais do Dasein, descrevendo assim seu modo originário: ser-no-mundo. De tal modo os entes que vem ao encontro e se mostram em significações dentro de uma situação ocupacional, ao que Heidegger nomeou de ocupação (Besorgen). A ocupação aqui pode ser entendida como um conhecimento próprio, no âmbito da lida, da "prática" com as "coisas" 
no mundo. É nesse sentido que o fenômeno se mostra ao Dasein, através do ser dos entes que vêm ao encontro, enquanto ao Dasein se dá uma compreensão destes entes não de modo teórico e sim ocupacional.

Portanto, na ocupação são demonstrados os cenários de aparição do fenômeno perante o Dasein, e isso se justifica na medida em que, neste momento, o ser dos entes abre-se em possibilidades; tais possibilidades garantem ao Dasein modos de compreender os entes no mundo, encontrando maneiras variadas de situações ocupacionais, pois o compreender possibilita uma rede de interpretações significativas de mundo. Essa situação ocupacional descrita acima pode ser entendida também por manualidade, pois a mesma constitui a mundanidade do mundo, porque o mundo é condição ôntica de possibilidade. O modo de ser desse ente que vem ao encontro do Dasein no mundo é a manualidade.

A mundanidade pode ser descrita também como um conceito ontológico pensado como a base da estrutura constitutiva do ser-no-mundo, sendo um existencial que garante o existir do Dasein, ele ser isso que ele é. Assim, notamos que a estrutura da mundanidade encontra-se vinculada à relação que o Dasein guarda com o mundo.

\section{CONSIDERAÇÕES FINAIS (ou Conclusão)}

$\mathrm{O}$ fenômeno do mundo, portanto, é o que possibilita que os entes se mostrem como entes à mão enquanto instrumentos. O manual que vem ao encontro do Dasein no mundo refere-se de algum modo à constituição ontológica da mundanidade do mundo, pois em todo manual o mundo já se encontra aberto às mais variadas possibilidades, pois é no mundo que ele se mostra à mão. Dentro da constituição do manual há o fenômeno da referência, isso significa que o manual carrega em si a ação de estar sempre referido a algo, sendo a conjuntura o traço ontológico desse manual. Nesta perspectiva em que o Dasein compreende a referencialidade dos intramundanos constitui a estrutura da mundanidade do mundo, pois o Dasein é familiarizado desde sempre a estas conjunturas e as compreende desde já pelo uso ocupado. Neste sentido introduzimos a ideia de significância, como aspecto da própria mundanidade do mundo, pois o movimento da referência tem ação de significar ao Dasein seus diferentes modos de ser em um mundo. O mundo em que o Dasein desde sempre está, essencialmente pertence à significância, pois é aí que residem as condições de possibilidades do Dasein, nas ações de compreender e interpretar mundo; a significância enquanto abertura, possibilita a movimentação do Dasein na conjuntura. Por fim, na manualidade é que se percebem os modos que possibilitam a mundanidade aos instrumentos, pois ela constitui-se como o princípio que fundamenta a mundanidade do mundo. 


\section{REFERÊNCIAS:}

\section{FONTES PRIMÁRIAS:}

HEIDEGGER, M. Ser e Tempo. Trad. Marcia de Sá Cavalcante. RJ: Vozes, 2014. Ser e Tempo. Trad. Fausto Castilho. RJ: Vozes, 2012. . Introdução à Metafísica. Rio de Janeiro: Tempo Brasileiro, 1999.

Pensadores). A essência da verdade. São Paulo: Nova Cultural, 1991 - (Coleção Os . Ensaios e Conferências. Petrópolis: Vozes, 2006. . Carta sobre o Humanismo. São Paulo: , 2005. Introdução à Filosofia. São Paulo: Martins Fontes, 2009. Marcas do caminho. Petrópolis: Vozes, 2008. . Ontologia: hermenêutica da facticidade. Petrópolis: Vozes, 2013.

\section{FONTES SECUNDÁRIAS:}

BLANC, M. F. O fundamento em Heidegger. Lisboa: Piaget, 1984.

BLANC, M. F. Introdução à Ontologia. Lisboa: Piaget, 2011.

CASANOVA, M.A. Compreender Heidegger. Petrópolis RJ: Vozes, 2010.

DUBOIS, C. Heidegger: introdução a uma leitura. Trad. Bernardo Barros Coelho de Oliveira. Rio de Janeiro. Jorge Zahar. 2004.

GIACOIA, OSWALDO. Heidegger urgente: introdução a um novo pensar. São Paulo: Três Estrelas. 2013.

LEVINAS, Emmanuel. Descobrindo a existência com Husserl e Heidegger. Lisboa: Piaget, 1997.

SAFRANSKI, R. Heidegger: um mestre da Alemanha entre o bem e o mal. São Paulo: Geração Editorial, 2005.

SCHMIDT, Lawrence K. Hermenêutica. Trad.Fabricio Ribeiro. Petrópoles, RJ. Vozes, 2013.

STEINR. G. As ideias de Heidegger. Trad. Álvaro Cabral. São Paulo. Cultrix. 1978.

STEIN. E. Aproximações sobre Hermenêutica. Porto Alegre: Edipucrs, 2004.

STEIN, E. Seis estudos sobre Ser e Tempo. Petrópolis: Vozes, 1988.

STEIN, E. Compreensão e Finitude: estrutura e movimento da interrogação heideggeriana. Ijuí: Ed. Unijuí, 2001.

\section{MATERIAIS DE REFERÊNCIA}

ABBAGNANO, N. Dicionário de Filosofia. Tradução da $1^{a}$ edição brasileira coordenada e revista por Alfredo Bossi; revisão da tradução e tradução de novos textos Ivone Castilho Benedetti. - $5^{\text {a }}$ ed. - São Paulo: Martins Fontes, 2007.

INWOOD, M. Dicionário de Heidegger. Tradução Luisa Buarque de Holanda; revisão técnica, Márcia S. Cavalcante Schuback - Rio de Janeiro: Jorge Zahar. Ed., 2002.

FLORENZANO, Éverton. Dicionario alemão-portugues. Rio de Janeiro: Edições de Ouro, 1963. 